تأثير مرض نقص النحاس على المكونات الاساسية لحليب النعاج

جنان علي الخالدي

فرع الصحة العامة البيطرية البنانية

كلية الطب البيطري

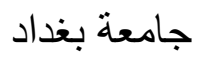

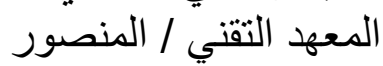

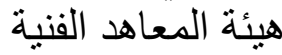

خلود خضير العكيلي

فر ع الصحة العامة البيطرية

كلبة الطب البيطري

جامعة بغداد

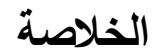

صباحا وقبل تتاول العليقة جمعت (30) عينة من حليب النعاج (10) منها اخذت من نعاج مصابة بمرض نقص النحاس و (20) اخرى من نعاج سليمة.

تم قياس النسبة المئوية للاهن والبروتين واللاكتوز والكلوريدات مع تحديد الأس الهيدروجين الهيني والوزن النوعي والرطوبة في عينات الحليب.

بعد أجراء التحليل الآحصائي لنتائج بعض التئي الفحوص الكيميائيه التي اجريت لعينات حليب

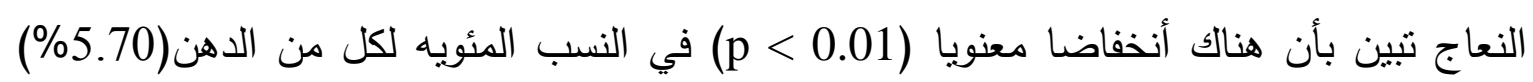

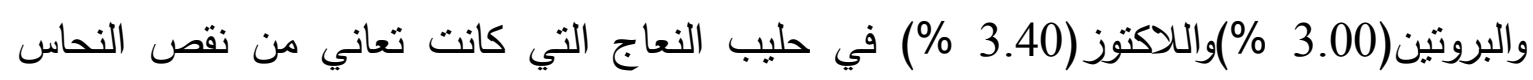

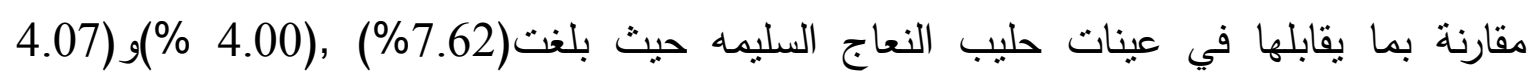
\%) على التوالي. لوحظ أرتفاع ملموس وواضح لكن غير معنوي(0.05 > p)في نسبة الكلوريدات (0.0921\%) في

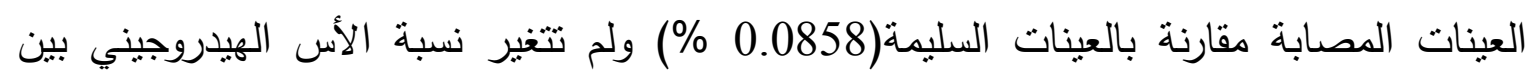

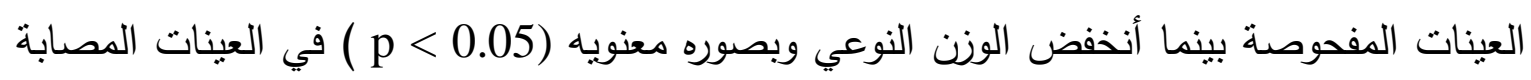
والبالغة (1.0338 ) مقارنة بغيرها من السليمة (1.0369).

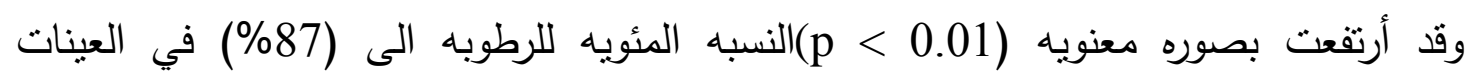
المصابه بينما لم تتجاوز النسبه (83\%)في العينات السليمه. 


\section{The Effect of Copper Deficiency on Essential Component Of Sheep Milk}

Khulood K.AL-Agealy

Dept. of Public Health

College of Vet. Med.

Baghdad University
Jinan A.AL-Khalidi

Al-mansurTechnigual

institute
Layla M.AL-Kinani

Dept. of Public Health

College of Vet. Med.

Baghdad University

\section{SUMMARY}

The main objective of this study was to determine the effect of copper deficiency on some milk constituents of ewes.(Thirty)raw milk samples have been collected in the morning and before feeding of the ewes,(10) of them from ewes suffering from copper deficiency and the other(20) milk samples were collected from healthy ewes. The percentages of fat ,protein ,lactose, chloride, specific gravity, moisture and the $\mathrm{pH}$ of milk were determined.

The results have shown that copper deficiency have an effect on the milk constituents where all milk samples collected from ewes suffering from copper deficiency had significantly $(\mathrm{p}<0.01)$ lower percentages of fat $(5.70 \%)$, protein $(3.0 \%)$, lactose $(3.4 \%)$

and specific gravity (1.0338) than those collected from healthy ewes that had (7.62\%),(4.0\%),(4.07\%) and (1.0369) respectively.

Data revealed that there was a significant $(p<0.01)$ increase in the percentage of moisture $(87 \%)$ and non significant $(p>0.05)$ increase in the percentage of chloride $(0.0921 \%)$ in the milk samples collected from ewes suffering from copper deficiency than healthy ones that had $(83 \%)$ and $(0.0858 \%)$ respectively. In addition to that no changes in the $\mathrm{pH}$ values between all milk samples were noticed.

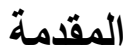

$$
\begin{aligned}
& \text { يعتبر مرض نقص النحاس من الأمراض الثائعة بين الأغنام اعتماداً على العلامات السريرية } \\
& \text { للحيوانات المصابة وانخفاض مستوى النحاس في مصل الدم. } \\
& \text { وقد اجري مسح حيواني لأغنام قطيع كلية الطب البيطري في بغداد لعام (2003) حيث سجل } \\
& \text { انخفاض ملحوظ في معدل مستوى النحاس في مصل الدم لتلألك الأغنام (1). } \\
& \text { كما استحدث مرض نقص النحاس في (15) نعجة عواسية من قطيع كلية الطب البيطري لدراسة }
\end{aligned}
$$

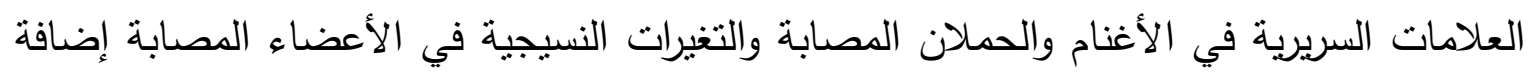

$$
\begin{aligned}
& \text { الى قياس مستوى النحاس و ألأنزيمات في مصل الدم ودراسة التغيرات في الصورة الاموية لام النعاج }
\end{aligned}
$$


المصابة وقد أضهرت نتائج التجربه علامات مرض نقص النحاس والتي شملت الهزال والضعف

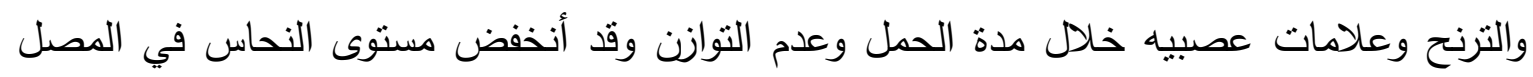

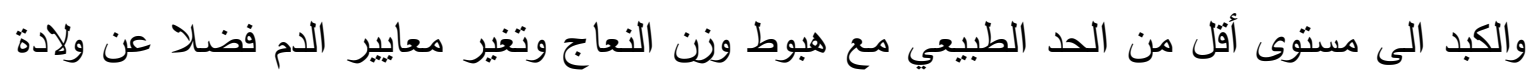

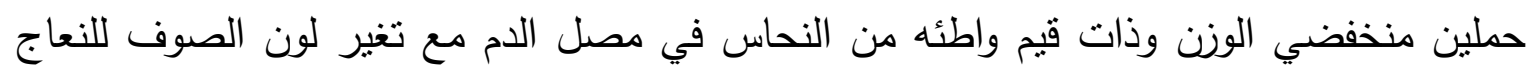

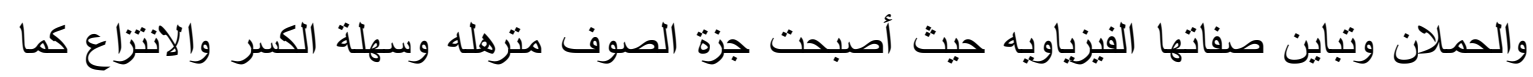
وضحت مقاطع الجهاز العصبي تغيرات نسيجيه كتكوين الفجوات والتتكس مع زوال النخاعين وبينت

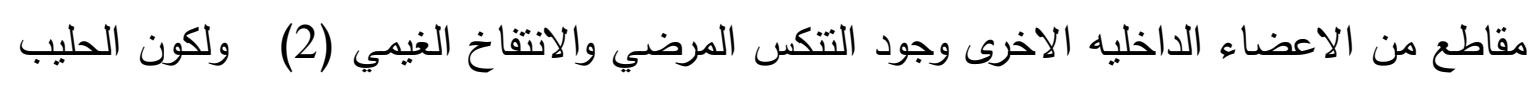

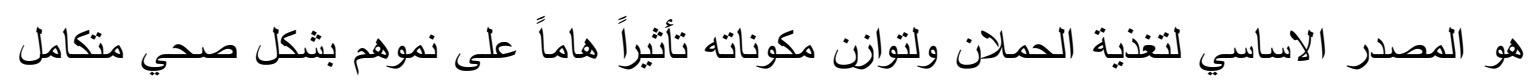

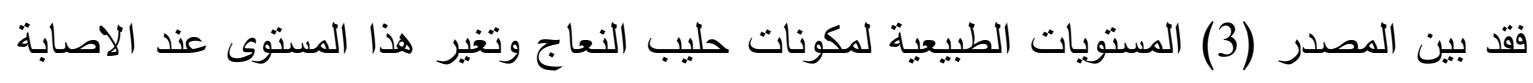
بمرض نقص النحاس. لهذا كان هدف هذه الدراسه هو قياس نسب مكونات حليب النعاج المصابة بمرض نقص النحاس

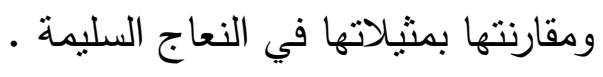

\section{المواد وطرائق العمل}

تم قياس كمية النحاس في مصل الدم بوحدة جزء من المليون(ppm) بأستخدام جهاز قياس شدة العمل

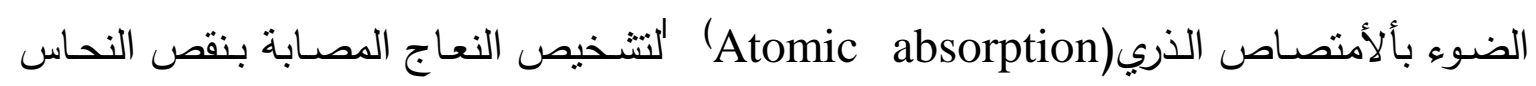

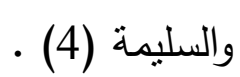

بعد مرور خمسة أسابيع من ولادة النعاج وقبل نتاول العليقة تم جمع (30) عينـة حليب في قناني

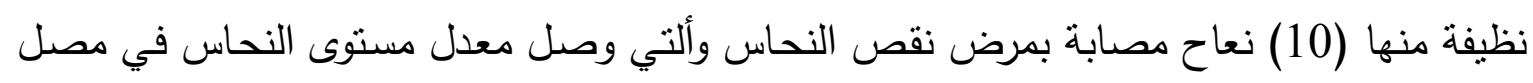
الدم فيها الى (0.53) جزء من المليون و (20) نعجة سليمة كان معدل مستوى النحاس في مصلها (0.88) (0.8 ) جزء من المليون. عُلمت كل عينة حليب برقم النعجة والتأريخ وتم أجراء الفحوصات الكيميائية لها حيث شملت هذه :

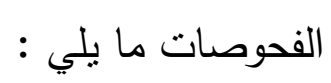

تقدير النسبة المئوية للدهن والنسبة المئوية للبروتين أعتماداً على (5) وتقدير النسبة المئوية لكل

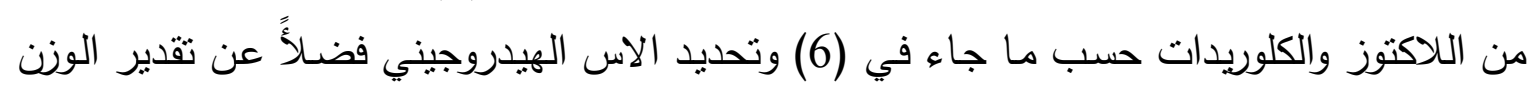

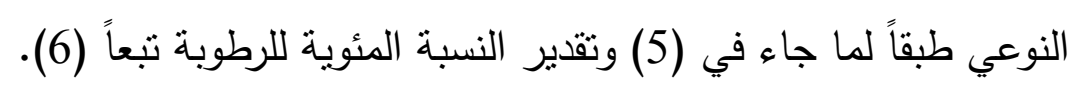

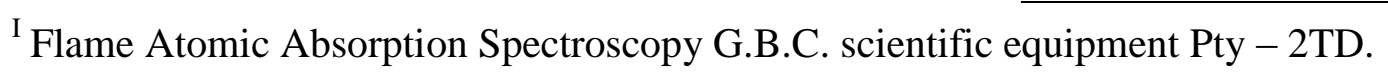




\section{النتائج}

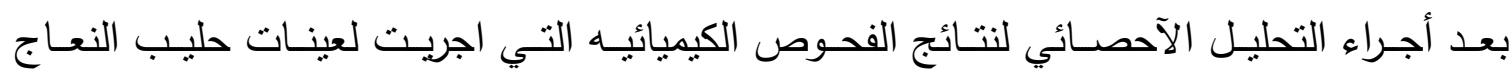

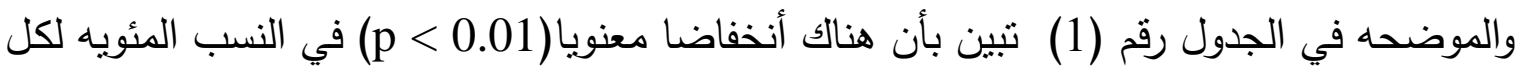

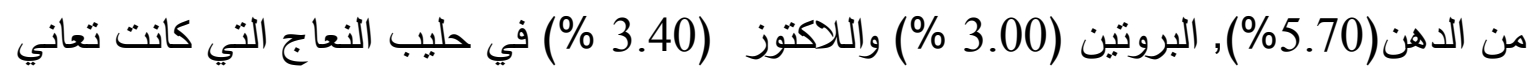

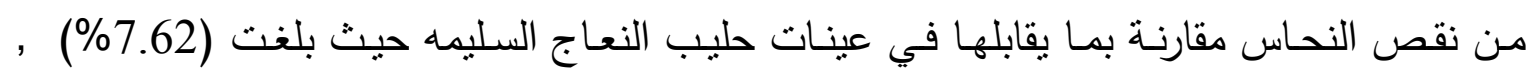

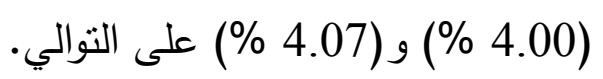

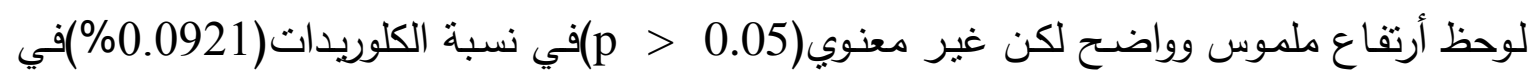

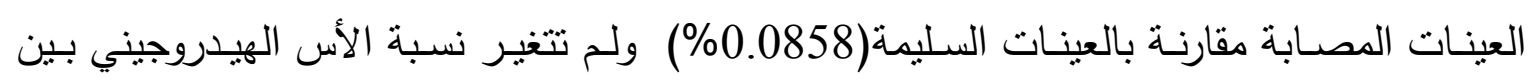

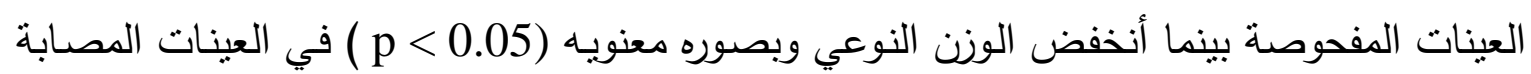

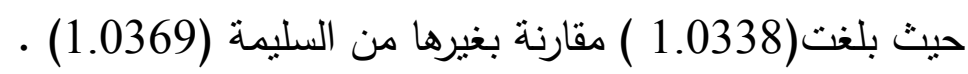

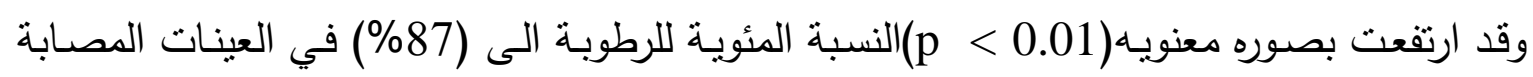
بينما لم تتجاوز النسبة (83\%) في العينات السليمة. 
المجلة الطبية البيطرية العراقية، المجلد 31، العدد 2، السنة 2007

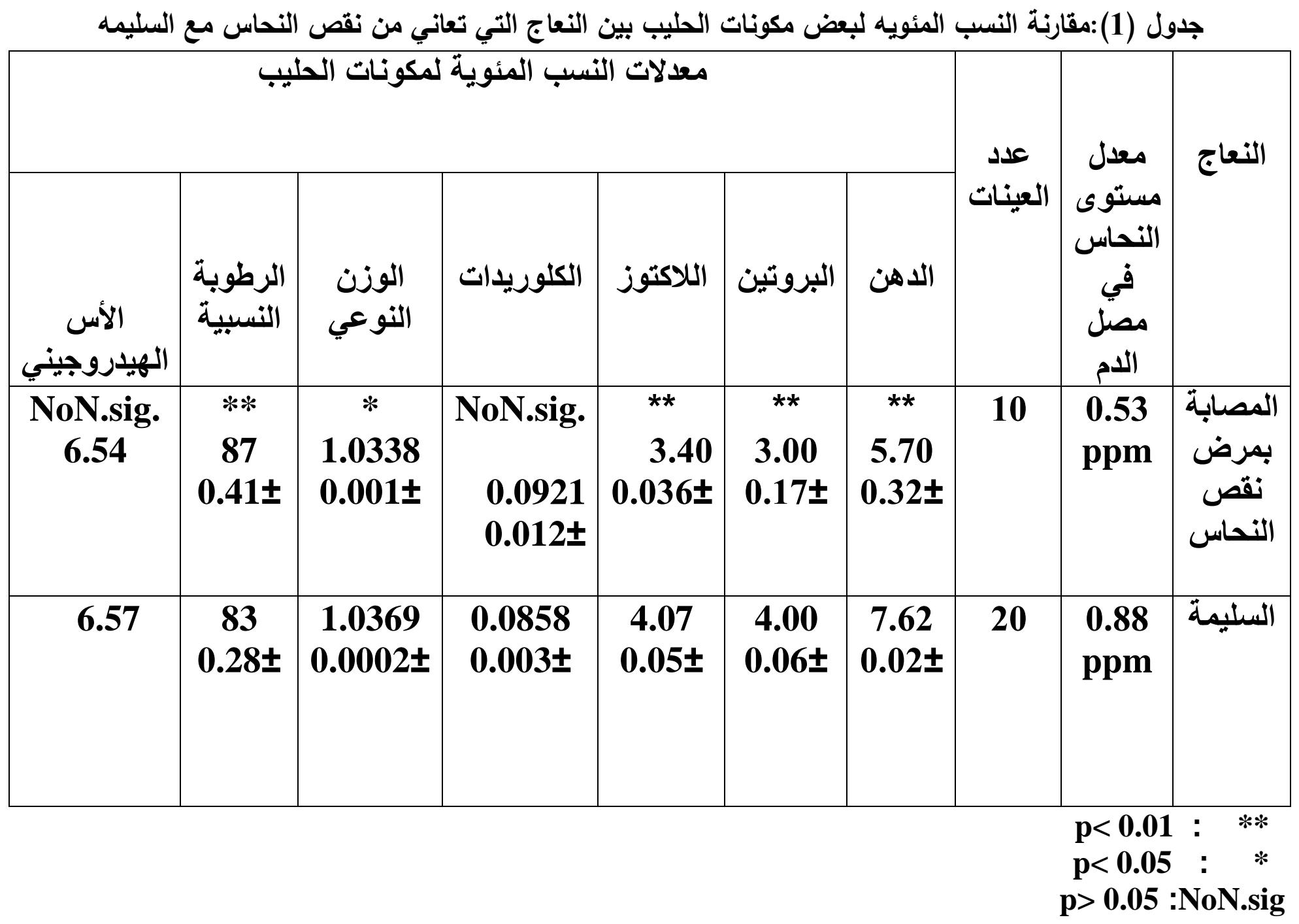




\section{المناقثة}

أظهر التحليل الكيميائي انخفاضا في النسبة المئويه للاهن والبروتين واللاكتوز والوزن النوعي في

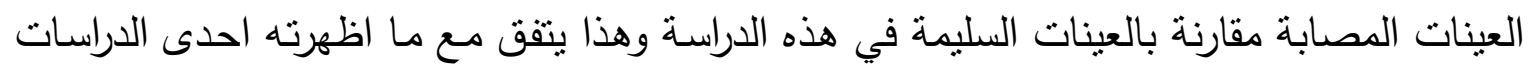
على حليب نعاج سليمة سنة (1992) ودراسة اخرى على حليب النعاج السليمة في ايرلندا سنة

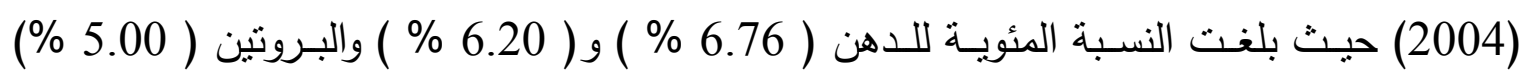
و (5.73\%) واللاكتوز

( 4.63 \% في كلا الدراستين على النوالي (7)و (8) وكان.

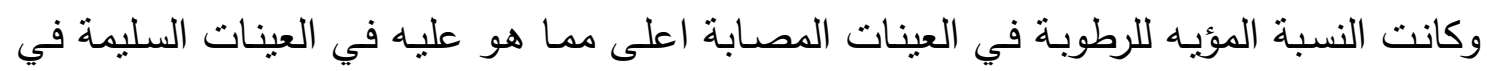

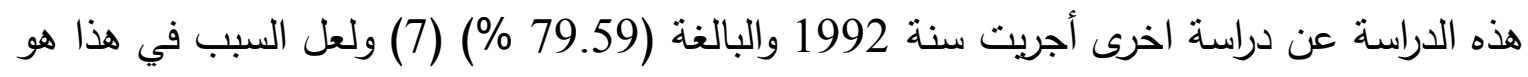

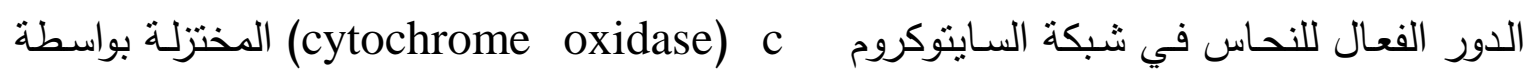

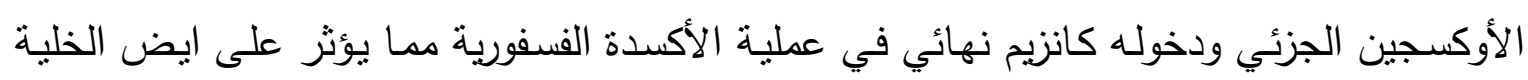

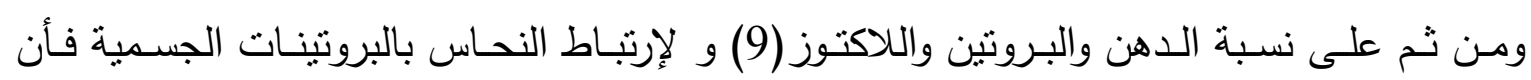

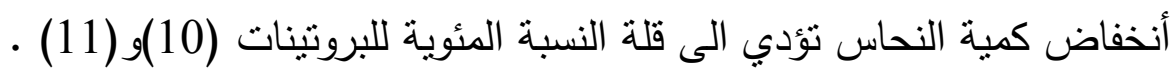

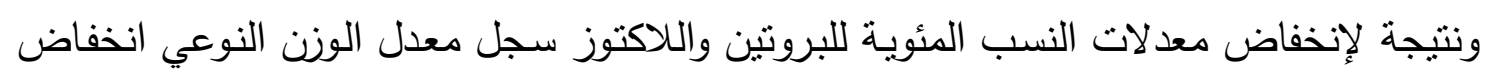
طفيف كونه يتتاسب طردياً مع نسبة المواد الصلبة اللادهنية في الحليب. وسجلت النسبة المئوية للكلوريدات ارتفاعاً في حليب النعاج المصابة نتيجة لأنخفاض نسبة اللاكتوز وذلك للمحافظة على الضغط التتافذي داخل خلايا الضرع حيث ان العلاقة عكسية بين اللاكتوز والكلوريدات.)

\section{المصادر}

1- السامرائي ، سعدي أحمد غناوي والعامري ، هند حامد (2003) ـ نقص المعادن الكافية في أغنام كلية الطب البيطري (بحث غير منشور). 2-الخالدي ، جنان علي (2004) • دراسة تجريبية لأستحداث مرض نقص النحاس في الاغنام

3 - Rodostits , O.M.; Hincheliff , K.W.; Cay , C.C and Blood ,D.C (2000). Diseases caused by deficiencies of mineral nutrients. Veterinary medicine. A text book of the diseases of cattle, sheep, pigs, goats and horses .9 th (ed). Bailliere Tindall . London. England. 
4- Dawson , J.B .; Ellies , D.J. and Newton , J. Ts. (1968) . Direct estimation of copper in serum and urine by atomic absorption spectroscopy. Clin . hina. Acta. 21:33

5-Marth,E.H.(1978). Standeredmethods for the examination of dairy products .14Th (ed). Amer. Public. Health. Assoc. Washington.

6- Henry V.A and Newlander,J.A.(1981).Chemistry and Testing of Dairy Products . Fourth Edition AVI.Publishing Company , INC. Connecticut , USA.

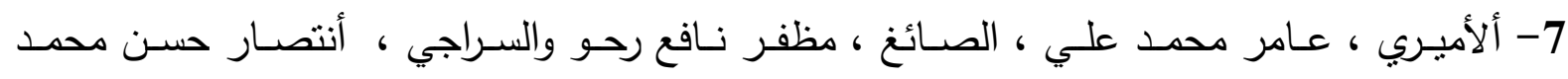

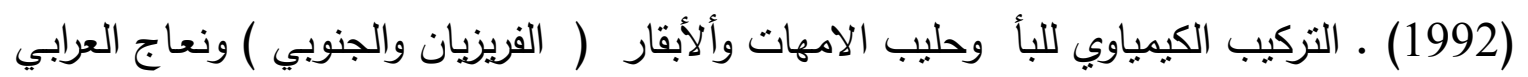

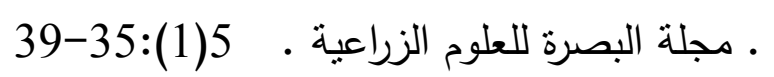

8- Hallgrimsson , S.S. and Olafsson , H.B. (2004). Experiments of sheep milking in Iceland. Milking sheep. (INt).

9- Griffiths , D.E. and Wharton . D.C. (1961) . Studies of the electron transport system xxxv. Purification and properties of cytochrome oxidaes J. Biol . Chem. 236:1850-56.

10- Evans, G. W. (1973) Copper homostasis in mammalian system. Physinol. Rev. 53.535-70

11- Milne, P.B. and Wes wig, P.H. (1968). Effect of supplementary copper on blood and liver copper containing fractions in rats. J. Nutr. 95:429-33 